\title{
The Social Perspective Taking Process: What motivates individuals to take another's perspective?
}

\section{Citation}

Gehlbach, H., Brinkworth, M. E., \& Wang, M.-T. (2012). The social perspective taking process: What motivates individuals to take another's perspective? Teachers College Record, 114(1), 197-225.

\section{Permanent link}

http://nrs.harvard.edu/urn-3:HUL.InstRepos:11393841

\section{Terms of Use}

This article was downloaded from Harvard University's DASH repository, and is made available under the terms and conditions applicable to Open Access Policy Articles, as set forth at http:// nrs.harvard.edu/urn-3:HUL.InstRepos:dash.current.terms-of-use\#OAP

\section{Share Your Story}

The Harvard community has made this article openly available. Please share how this access benefits you. Submit a story. 
The Social Perspective Taking Process:

What motivates individuals to take another's perspective?

Manuscript submitted February 12, 2010

Revision submitted July 23, 2010

Final draft submitted August 17, 2010

Running Head: SOCIAL PERSPECTIVE TAKING MOTIVATIONS 


\section{Cover Page:}

Hunter Gehlbach

Hunter_Gehlbach@gse.harvard.edu

(617) 496-7318

328 Longfellow Hall

13 Appian Way

Cambridge, MA 02138

Hunter Gehlbach is an assistant professor at Harvard's Graduate School of Education. His primary interests lie in using social psychological principles and research to improve schools. He also maintains an active research interest in effective questionnaire design. Recent publications include "Motivated thinkers and the mistakes they make" in Advances in motivation and achievement: Social psychological perspectives (with Maureen Brinkworth) and a forthcoming article in Educational Psychology Review entitled "The social side of school: Why teachers need social psychology.”

Maureen E. Brinkworth meb308@mail.harvard.edu (617) 945-1526

Maureen Brinkworth is a doctoral candidate at Harvard's Graduate School of Education. She is interested in how social perspective taking impacts different aspects of secondary classrooms - particularly the relationships between teachers and students. Her recent work includes "Motivated thinkers and the mistakes they make" in Advances in motivation and achievement: Social psychological perspectives (with Hunter Gehlbach).

Ming-Te Wang miw710@mail.harvard.edu

(734) 647-1914

Ming-Te Wang recently completed his doctorate at Harvard University's Graduate School of Education. His research interests focus on adolescent development in school, family, and community settings, achievement motivation and engagement, and low-income community contexts. Recent publications include "Adolescents' perceptions of school environment, engagement, and academic achievement in middle school" (with Rebecca Holcombe in American Educational Research Journal) and has a forthcoming article in Journal of Educational Psychology entitled "Longitudinal trajectories of three dimensions of school engagement during adolescence.”

Brief article description

Social perspective taking - the motivation and ability for individuals to discern the thoughts and feelings of others - is linked to a host of desirable outcomes in schools. Yet, little is known about the process that motivates individuals to engage in this fundamental social process. This mixed-method study describes 13 factors that impact individuals' motivation to try to take the perspective of others. 


\section{Structured Abstract}

Background/Context:

A growing literature describes multiple benefits of social perspective taking - many of which are particularly important for schools. Despite these potential benefits for administrators, counselors, teachers, and students, little is known about social perspective taking as a process.

Purpose/Research Question:

If educational researchers are ultimately to design interventions to help improve the perspective taking capacities of those in schools, they need to fully understand the underlying process. Particularly important is the need to understand: What initially motivates individuals to take the perspective of others?

Participants:

To investigate this question, a sample of 18 adults from an array of different professions (who were nominated as adept perspective takers) and 13 high school students (who were nominated as struggling with social perspective taking) participated in the study.

Research Design:

Participants completed a survey, a performance task, and in-depth interviews as part of this mixed-method, exploratory study. The interviews served as the primary source of data and were coded for evidence of what triggered (or inhibited) participants' motivation to engage in the social perspective taking process.

Findings:

The interview data established the existence of at least thirteen specific factors that impacted participants' motivation to engage in social perspective taking across a wide array of contexts. Seven factors generally enhanced individuals' motivation to engage in social perspective taking; three factors were mixed; and three factors inhibited their motivation.

Conclusions/Recommendations:

This research indicates that not only might individuals be motivated to engage in social perspective taking through multiple pathways, but that these pathways might be combined and/or interact with one another. These motivating factors raise important issues for further research. In addition, at a practical level, they provide a foundation for developing structures to motivate individuals in schools to engage in perspective taking more often.

Keywords: social perspective taking, motivation, social processes, social interaction 


\section{Executive Summary:}

Increasingly, research describes multiple benefits of social perspective taking (SPT) - individuals' motivation and ability to discern the thoughts and feelings of others. Many of these benefits are particularly important for administrators, counselors, teachers, and students in their daily lives at school. Yet, little is known about the process that motivates individuals to engage in this fundamental social process. This study sheds light on the SPT process by exploring the research question: What initially motivates individuals to take the perspective of others? By illuminating part of the SPT process, this study strives to help develop a foundation of knowledge from which scholars can design interventions that might ultimately improve the perspective taking capacities of educators and students in school settings.

Past research has investigated SPT ability (e.g., Ickes, 2003) and motivation (e.g., Hall, Blanch, et al., 2009) through a variety of correlational and experimental approaches. Although this work has reinforced the association of SPT with important educational outcomes, it has left unanswered questions about how the process of SPT actually unfolds. In particular, we have little knowledge of how the process even begins i.e., what motivates people to engage in the SPT process initially.

To investigate this important question, 18 adults and 13 high school students participated in the study. The adults came from an array of professions which required them to use SPT in different ways in their positions; they were identified by nominators as likely to be adept perspective takers. By contrast, the students were nominated as struggling with SPT or were participants in a program designed to assist students with Asperger's symptoms. Through this sampling approach we maximized heterogeneity with regard to participants' developmental level of SPT, the range of settings in which they approached SPT tasks, and their SPT motivation and ability. Semi-structured interviews served as the primary source of data. In the interviews, participants described situations in which they had engaged in SPT and reflected on what motivated them to engage in SPT in these different instances. Interview transcripts were coded for evidence of motivational triggers (or inhibitors) of SPT. Participants also completed a survey (assessing their SPT propensity, SPT confidence, and SPT importance), and a performance task (assessing their SPT ability). 
The interview data established the existence of at least thirteen specific factors that impacted participants' motivation to engage in social perspective taking across a wide array of contexts. Seven factors generally enhanced perceivers' motivation to engage in social perspective taking. These factors included:

1) Whether the SPT target or situation was deemed to be high stakes (e.g., the suicidal patient of a counseling psychologist)

2) The pursuit of prosocial goals (e.g., a teacher wanting to help a student)

3) Striving to learn more about the situation (e.g., a participant who was trying to understand a new work environment after his job changed)

4) Attempting to initiate, maintain, or repair a relationship with a target (e.g., a student who was curious to get to know a new boy in her school)

5) Needing to exert social influence over the target (e.g., an educator working abroad who needed to secure the cooperation of several families)

6) Whether the perceivers had an intrinsic interest in taking the perspective of others (e.g., a teacher who enjoyed “people watching” in her school's cafeteria)

7) Hoping to acquire self-knowledge (e.g., a teacher on a job interview who tried to understand what her interviewers thought of her).

Three factors were mixed; they sometimes enhanced and sometimes inhibited perceivers' SPT motivation:

8) Perceivers' level of emotional regulation (e.g., participants who were occasionally too angry to take the perspective of others)

9) Whether perceivers conceptualized engaging in SPT as part of their role or identity in a given situation (e.g., a trial lawyer who felt part of his job was to take the perspective of jurors)

10) Familiarity (e.g., a participant who was more motivated to take the perspective of others when abroad because she was less familiar with that culture)

Finally, three factors inhibited perceivers' SPT motivation:

11) A lack of energy (e.g., a teacher who did not take the perspective of her coworker because it was too early in the morning and she was too tired)

12) Hubris (e.g., a student whose desire to be "right" outweighed her desire to try to take her sister’s perspective) 
13) Being under too great a cognitive load (e.g., teachers trying to take the perspective of all their students at the same time in a large class).

Three themes emerged as particularly important at both a theoretical and practical level. First, individuals within schools might be motivated to take the perspective of others through multiple pathways. For example, even if a teacher believes discerning the thoughts and feelings of her students is not part of her role, she might be motivated to engage in SPT through a discussion with an administrator or colleague about how high stakes her subject area is, and how SPT will enhance her ability to convey her content effectively. Second, the findings indicate that these pathways may be combined. Thus, educators who want to bolster SPT motivation among themselves or among their students might structure situations so as to coordinate several of these specific motivating factors. Finally, these factors may interact with one another. In other words, whether someone who views SPT as an important part of their role actually engages in SPT in a particular situation may depend on their familiarity with that target, how well they are regulating their emotions, or any number of the other factors. In these ways, the motivating factors described in this study provide a foundation from which educational researchers can develop interventions to motivate more perspective taking between individuals in schools. 


\section{The Social Perspective Taking Process:} What Motivates Individuals to Take Another's Perspective?

If I could be you, if you could be me

For just one hour, if we could find a way

To get inside each other's mind

If you could see you through my eyes

Instead of your own ego I believe you'd be

I believe you'd be surprised to see

That you've been blind

Walk a mile in my shoes

just walk a mile in my shoes

Before you abuse, criticize and accuse

Then walk a mile in my shoes

-- Elvis Presley (1970)

As Elvis observes, people often wish to get inside the heads of others as a means to better understanding their point of view. Perhaps even more frequently, individuals wish that others could better see and understand the world from their perspective. Yet, people are often frustrated that others never seem to even attempt "walking a mile in their shoes."

Although understanding others is important in many settings, it is especially crucial in schools. School administrators must balance the wants and needs of multiple constituents including parents, teachers, local politicians, and students while brokering compromises between them. School counselors must figure out students' thoughts and feelings if their advice is to be helpful. Teachers need to anticipate which instructional approaches will best motivate and facilitate learning for different students. As students prepare for participation in a much more global society, they increasingly need to understand the points of view of others who are quite different from themselves. These are just a few illustrations of the wide array of activities within schools for which taking the perspective of others is fundamental. Thus, a critical question arises as to how to enhance this capacity for individuals within school communities.

Social perspective taking (SPT) is the process through which a perceiver discerns the thoughts, feelings, and motivations of one or more targets. SPT includes appreciating the point of view of those with different values and trying to understand how others perceive the situation. Although commonly viewed as the ability to understand people accurately, SPT is an aptitude that also includes the motivation to employ that ability 
(Gehlbach, 2004a). In other words, for successful perspective taking to occur, a perceiver must first be motivated to try to understand one or more targets and then must engage in a process that allows him or her to accurately ascertain the target's mental state. This broad conceptualization of SPT encompasses domains such as empathic accuracy - essentially equivalent to SPT ability (Ickes, 1997); nonverbal behavior (e.g., Ambady \& Rosenthal, 1993); everyday mindreading - judgments about what others think, feel, and want (Ames, 2004); and social projection - a specific SPT strategy in which people "put themselves in other people’s shoes” and expect others to be similar (Krueger, 2007). SPT also overlaps with areas such as interpersonal sensitivity - accuracy in judging or recalling others' behavior and/or appearance (Hall, Andrzejewski, \& Yopchick, 2009); emotional intelligence - information processing about emotions (Mayer, Salovey, \& Caruso, 2008); and social role-taking (Selman, 1975b). Of these different forms of interpersonal perception, the present conception of SPT is distinct because of its equivalent emphasis on motivation and ability. Important practical implications follow from this theoretical distinction - enhancing people’s SPT can occur through improving perceivers' accuracy or by motivating them to engage in the SPT process more frequently.

Several strands of research on SPT - including experiments (e.g., Galinsky \& Moskowitz, 2000), examinations of SPT ability (Ickes, 2003), and investigations of SPT motivation (Hall, Blanch, et al., 2009) - have connected this aptitude to many important outcomes in schools. As a result, educational researchers now need to understand the SPT process so that they might begin to develop interventions to enhance this aptitude in students and educators alike. In other words, the research demonstrating that SPT is important now needs to be complemented with a better understanding of how people engage in the SPT process if we are to improve SPT for those within school communities.

This article extends the literature on SPT in an important new direction by starting to illuminate the very beginning of the SPT process - how the SPT process is triggered initially. Specifically, we ask: What specific factors motivate individuals to engage in SPT? After establishing the importance of SPT within school contexts, we review past work on SPT motivation to situate our study within the larger SPT literature. We then investigate this research question on a heterogeneous, purposeful sample of adults and students to capture as full a range of these motivations as possible. After describing our 
data collection and coding procedures, we identify and categorize the 13 specific triggers that our participants reported as motivating them to engage (or not engage) in the SPT process. Our discussion of this taxonomy focuses on the practical importance of these multiple avenues through which people are motivated to engage in SPT in schools and how this new knowledge might direct future school-based research.

\section{The Implications of SPT for Schools}

Three approaches to studying SPT - conducting experiments, assessing ability, and investigating SPT dispositions - have each signaled SPT's importance to schools.

Although fewer studies have examined SPT in school contexts directly, many studies have established the importance of SPT within education by linking it to valued educational outcomes in other settings. In the aggregate, this research indicates that an important next step for researchers interested in improving education is to learn more about the underlying SPT process with an eye towards teaching SPT aptitude to different populations within schools.

Although SPT experiments have usually been set in laboratories, the outcomes examined are central to fostering successful school communities. Participants instructed to engage in SPT have stereotyped others less (Galinsky \& Moskowitz, 2000) and improved their negotiation capacities (Galinsky, Maddux, Gilin, \& White, 2008) - key capabilities for teachers working with students, particularly in diverse schools where teachers may need to negotiate compromises with students from different backgrounds than their own. In other important contributions from experimental SPT work, Richardson, Green, and Lago (1998) have shown that participants instructed to engage in SPT responded less aggressively when provoked; others have shown increases in altruistic behavior (Batson, Early, \& Salvarani, 1997; Batson, Sager, et al., 1997). In the context of the continuing school violence problems that plague many districts, less aggressive, more benevolent behavior are similarly important outcomes.

The second domain of SPT research - the work on SPT ability - has linked this ability with learning, achievement, and relational outcomes. Of particular relevance to schools are the findings that students who are more accurate perceivers learn more (Bernieri, 1991), receive higher ratings from teachers (Halberstadt \& Hall, 1980), and get 
higher grades (Gehlbach, 2004b). In addition to these academic outcomes, Gleason, Jensen-Campbell, and Ickes (2009) found that children who were lower in SPT accuracy were more likely to experience adjustment problems. Research on individuals in close relationships has shown that more accurate perceivers offer more skillful support of others (Verhofstadt, Buysse, Ickes, Davis, \& Devoldre, 2008); accurate perceivers are also more likely to communicate effectively (Nickerson, 1999). Given the importance of administrators communicating their support to teachers and teachers being supportive in their relationships with students (Juvonen, 2007; Wentzel, 1997), it seems likely that SPT accuracy plays a key role in many of the interpersonal relationships within schools.

Third, although fewer scholars have examined SPT as a general disposition, the propensity to engage in SPT has also been linked to important educational outcomes. Much of this work has treated SPT as a personality trait in which individuals who are higher on measures of SPT are more motivated to engage in the SPT process in general. Students who reported taking the perspective of others more regularly chose more effective strategies for resolving conflicts in classroom-based scenarios (Gehlbach, 2004b). Being motivated to engage in SPT has been theoretically linked to students' better understanding certain content areas such as history (VanSledright, 2001). Within the counseling literature, Corcoran and Mallinckrodt (2000) found that those higher in SPT also had greater social self-efficacy and healthier attachment profiles.

This combination of correlational studies of SPT ability and motivation with laboratory experiments provides strong, convergent evidence that SPT aptitude is yoked with an array of beneficial academic and social outcomes for individuals within schools. Thus, future research that ascertains how to improve the SPT ability and motivation of educators and students would be particularly valuable. Before effective interventions can be developed however, the SPT process must be understood much more fully. For example, interventions to help people engage in SPT more often cannot be developed until we understand when and how people engage in (or fail to engage in) SPT in the first place.

\section{SPT Motivation - A Focus on Specific Motivational Factors}

People engage in SPT because the combination of specific environmental or personal factors interacting with a perceiver’s general personality traits overcomes 
whatever barriers might inhibit that perceiver from engaging in SPT. Of these two aspects of the SPT process we focus on first part of that process - what types of factors trigger people to engage in SPT initially? Although many facets of the SPT process are ripe for investigation, we explore which specific factors trigger SPT motivation for three reasons.

First, at a theoretical level, prior research has provided some knowledge about the general dispositions that play a role in SPT motivation; there is scant knowledge exists about the specific factors that motivate engagement in the SPT process. Past research has generally taken one of two approaches to examining SPT motivation. In one approach, scholars have examined SPT motivation as a general disposition or personality trait in relation to other outcomes. In other words, individuals are differentiated in terms of whether they see themselves as the kind of person who tends to/is motivated to engage in SPT. Much of this research has utilized Davis’ (1983) SPT scale of his Interpersonal Reactivity Index. Specifically, this measure asks people to self-report how well certain statements describe them such as, "I try to look at everybody's side of a disagreement before I make a decision.” Research using this approach has shown SPT to be a relatively stable trait that tends to increase over time during high school (Davis \& Franzoi, 1991). In addition, those scoring higher on this type of a measure of SPT tend to have higher selfesteem (Davis, 1983), have more 'integrating' and 'compromising' - as well as less ‘dominating’ conflict resolution styles (Corcoran \& Mallinckrodt, 2000), and maintain more positive overall psychological well-being (Gruhn, Rebucal, Diehl, Lumley, \& Labouvie-Vief, 2008).

As an alternative approach, some have looked at SPT motivation by examining phenomena that might facilitate it. For example, despite confidence in one's SPT ability having minimal bearing on actual SPT ability (Ames \& Kammrath, 2004; Hall, Andrzejewski, et al., 2009; Realo, et al., 2003), it does relate to the overall frequency with which people report engaging in SPT (Gehlbach, 2005, April). Other research signals that similarity motivates people to engage in social projection - a particular approach to SPT (Robbins \& Krueger, 2005). More recent research on similarity and SPT further indicates that similarity may cause the targets of SPT attempts to rate the perceivers as being more understanding (Hodges, Kiel, Kramer, Veach, \& Villanueva, 2010). Thus, past research 
has shed some light on associated dispositions that may encourage people to engage in SPT more frequently.

In sum, knowledge of both specific situational factors and general dispositions is required to understand people’s behavior (Mischel \& Shoda, 1995), but within the domain of SPT motivation, much less is known about the former. Thus, learning about the range of specific factors that lead to SPT motivation appears to be a more unique, equally important, scientific contribution than further examining general dispositions.

The second reason we focus on which specific factors motivate people to engage in SPT is pragmatic. Because people must first be motivated to engage in the SPT before other aspects of the process occur, there is a sense in which all other questions about the SPT process are subsidiary to this one. Without understanding how to get people initially engaged in SPT, research that might help improve other aspects of SPT aptitude will be largely irrelevant. Because this research is designed to help scholars think about crafting interventions to bolster SPT in schools, this aspect of the SPT process is particularly important to address.

Finally, adapting contexts seems like a potentially more promising pathway for bolstering people’s engagement in SPT than does trying to change people’s general dispositions to engage in SPT. In other words, while getting a highly egocentric adolescent or a "my-way-or-the-highway" school administrator to change their personality seems destined for failure, while assigning them roles to engage in SPT in certain situations may well change their approach to different interactions.

\section{Methods}

To meet the study's goals of documenting and understanding what specific factors motivate individuals to engage in SPT, we developed a two-pronged methodological approach. First, we obtained a unique, heterogeneous sample of different kinds of perspective takers to help record as a full a range as possible of specific factors that influenced SPT motivation. Second, we structured our interviews to provide a detailed understanding of how these specific factors functioned, e.g., what contextual factors were present during the SPT attempt, what were participants' goals for a given interaction, etc. This methodological approach allowed us to glean insights into the inception of the SPT 
process across a wide variety of individuals, situations, and types of interpersonal interactions.

\section{Participants}

In designing our sample, we balanced our competing goals of fully documenting the range of specific factors that might impact SPT motivation with the need to understand these specific factors in depth. In other words, we needed to constrain the sample size while maximizing its heterogeneity. In addition, we wanted to ensure that the research could be applied to school settings. We strove to balance these tensions in three ways.

First, for this research to ultimately facilitate the development of SPT interventions for both educators and students alike, it seemed important to sample from both of these populations. Moreover, sampling from students and adults would still allow us to fully document the range of specific factors even if important developmental differences emerged. Because SPT ability is rooted in the type of abstract thinking that generally emerges during adolescence (Keating, 1990), we selected high school students as the developmental lower bound of our participant pool ${ }^{1}$.

Second, we felt that it would be a mistake to limit the sample to only individuals from within schools. Doing so would impede our chances of learning the full range of the specific factors that motivate people to engage in SPT. Furthermore, individuals' experiences from other professional contexts might offer new insights that could benefit education. Consequently, we oversampled educators, but broadened the remainder of the adult sample to include individuals from an array of professions that engaged in SPT in a variety of ways. Specifically, our adult participants included six educators, as well as army interrogators, counseling psychologists, customs officials, police detectives, car salesmen, and a trial lawyer. By sampling individuals from these particular vocations we hoped to learn about the specific factors that motivated SPT in different contexts - though contexts that might be applicable to those in school settings. For example, car salesmen might be motivated to take the perspective of their customers to determine the best approach to

\footnotetext{
${ }^{1}$ Accordingly our results will not necessarily represent the specific factors that motivate the qualitatively different types of SPT that occur at earlier developmental stages (see Selman, 1975a for a description).
} 
making a sale in a roughly the same way that teachers might benefit from figuring out their students as a means to "selling” the curricular content more effectively.

Third, different motivational factors might be more salient for individuals with different levels of SPT aptitude. For example, teachers who are adept or regular perspective takers might be highly motivated by the challenge of figuring out the pokerfaced student in the back of their classroom. However, colleagues who are less adept or less frequent perspective takers might be unmotivated to make that same SPT attempt because of the difficulty of the task or their general reticence to engage in SPT. Therefore, we strove to sample from perspective takers who ranged in their SPT ability and propensity. Toward this end, when we solicited the student sample, we employed a nomination process to purposefully sample students who struggled with perspective taking. Specifically, we explained the study and defined "social perspective taking” to a group of teachers and administrators at a small, socio-economically and racially diverse private high school. They then nominated students who they felt "struggled in social perspective taking." Seven students for whom there was substantial consensus among the nominations participated from this school. We also recruited a group of students at a public high school who participated in a special program designed to help with issues of social anxiety and Asperger's-related symptoms; six of these students joined the study. We conducted a parallel nomination process for the adults in the sample by asking colleagues or supervisors which co-workers were particularly good at SPT. The top two or three nominees from each group were invited to participate.

Thus, our final sample included 13 high school students (11 male) and 18 adults (11 male). The sample was predominantly White (62\% in the student sample and $88 \%$ in the adult sample), with African-Americans and Asians comprising the other races. The mean age was 43.4 years old for the adults $(s d=11.5)$ and 15.9 years old for the students $(s d=1.3)$.

\section{Data Collection}

Because of the research showing how inaccurately people assess their own SPT ability (Ames \& Kammrath, 2004), we had concerns that judging the SPT capacities of others might be problematic for our nominators. Thus, we included supplementary 
measures to provide a check on the sample heterogeneity with regard to SPT ability and motivation. These measures are briefly described before detailing the main semistructured interview measure.

Survey measures. To assess participants' SPT motivation, we collected self-report data through three survey scales. The SPT Propensity scale (9 items; $\alpha=.77,95 \% \mathrm{CI}=$ $.65-.89)^{2}$ assessed how often participants reported engaging in SPT. This dispositional measure of SPT, which was adapted from the perspective taking scales used by Davis (1983) and Gehlbach et al. (2008), provided a general assessment of how frequently participants engaged in the SPT process. Using an expectancy-value approach (Eccles, Wigfield, \& Schiefele, 1998), we developed two new scales to assess related SPT dispositions. We measured participants’ confidence in their SPT abilities (i.e., their expectancies that they could accurately read a target) through an SPT Confidence scale (8 items; $\alpha=.88,95 \% \mathrm{CI}=.80-.94)$. We assessed how important participants' thought it was to engage in SPT (i.e., their valuing of SPT) through a SPT Importance scale (7 items; $\alpha=.69,95 \% \mathrm{CI}=.48-.84)$. The complete items are listed in the Appendix.

Performance task. To assess participants' SPT ability, we adapted the video task used by Gehlbach (2004b). To complete the task, our participants viewed a series of videos in which two individuals had a conversation. Participants reported which of a list of thoughts and feelings they believed each individual had/had not experienced during the conversation. Responses were scored by matching participants' answers against the selfreports of the individuals from the video-taped conversations. Thus, by chance alone participants had a 50\% probability of getting each answer right. Total SPT accuracy scores were computed by averaging participants’ correct and incorrect answers across all 142 thought and feeling items from the twelve targets in the six videos. The reliability was $\alpha=$ $.77,95 \% \mathrm{CI}=.64-.87$.

Interview. To address our primary question of what motivated participants to engage in SPT in specific situations, we conducted semi-structured interviews with participants. Specifically, we asked participants to, "think of a situation in which you were really motivated to take another person's perspective” as well as a time when they were

\footnotetext{
${ }^{2}$ Confidence intervals for scale reliabilities were computed using Barnette’s (2005) ScoreRel CI Excel program.
} 
particularly unmotivated. In addition, participants described a time they remembered taking somebody else's perspective and doing a particularly good job (i.e., being accurate in their read of the target) as well as a time when they did not do a good job (i.e., were inaccurate). Because most people spend little time metacognitively evaluating their SPT processes, the interviewers frequently asked follow-up probes (e.g., What was the context/issue? Who was involved? Why do think you tried so hard in this situation?) to help participants better recall their SPT process.

Data collection procedures. After identifying potential participants through the nomination procedures described above, we contacted the nominated individuals (and their parents in the case of minors). We met most participants on our university campus or at their school/place of work. The researchers guided participants through each of these data collection procedures (survey, performance task, and interview) in the order described above $^{3}$. The procedures lasted about two hours for most participants. Three individuals declined to be interviewed due to the sensitive nature of their work.

Interview coding procedures. All interviews were recorded and transcribed. To establish a reliable coding system, the research team first listed a small number of codes hypothesized to be important based on a review of the literature. For example, the desire to learn more about oneself within the context of identity formation has been posited to motivate individuals to engage in the SPT process (Enright \& Deist, 1979), so 'selfknowledge' was an initial code. Next, two transcripts were selected and read by all three coders for potential categories and subcategories of SPT motivations. A tentative set of codes was culled from the literature and these transcripts. For each motivation code a definition, indicators of what characteristics should be present or absent, qualifications, exclusions, and examples were compiled into a preliminary codebook. Using this codebook, the three coders completed a second round of coding on new transcripts, which led to minor revisions to the coding scheme. For the final coding, all transcripts were coded in small sets (roughly 3 transcripts) using these final codes. Within each set of transcripts, at least one transcript was coded by two coders. Consensus was reached on any codes that differed through conversations with the first author.

\footnotetext{
${ }^{3}$ After the performance task, participants also completed a 'think-aloud' task as a part of additional research on the SPT process.
} 
We assessed the reliability of the final coding by comparing the codes for those transcripts that were reviewed by two researchers. Agreement ${ }^{4}$ was calculated as follows: we assigned a point each time that raters agreed in their coding of a certain segment of transcript; a zero was assigned for segments of transcript where a code was identified by only one coder (i.e., the other coder saw no codes) and where the same segment of transcript was coded differently by each coder; agreement was computed by dividing the total number of codes where both raters agreed by the total number of codes generated. The overall agreement for the three coders was $89 \%$.

\section{Results}

Before describing the specific SPT motivations that our participants noted in reflecting on different SPT episodes, we briefly report the results of the analyses that establish the level of heterogeneity in our sample.

\section{Sample Heterogeneity}

As Table 1 indicates, we achieved substantial variability along the dispositional and ability dimensions of SPT. In the table, the survey scale scores have been transformed to parallel the performance task so that possible scores range on each of these measures range from 0 to 1 . Participants' scores from the SPT propensity and SPT confidence scales ranged over about two-thirds of the full scale and over about half of the SPT importance scale. For the performance task, the actual score range of .54 to $.88(M=.67, s d=.07)$ also represents about two-thirds of the possible scale range after accounting the fact that participants should get half their answers correct by chance alone. Thus, our sample included substantial variability along both dimensions of SPT.

As expected, much (though not all) of this variability occurred between the two groups that we sampled. Adults were motivated to engage in SPT more frequently than students ( $M=.73$ versus $.58 ; t_{(28)}=2.87, p=.008$; Cohen's $\left.d=1.06\right)$. Adults were also more accurate perspective takers ( $M=.69$ versus .63; $t_{(25.5)}=2.75, p=.011$; Cohen's $d=$ .95) than the students in our sample. However, adults and students did not differ

\footnotetext{
${ }^{4}$ We computed agreement, rather than Cohen's Kappa, because there were no clear units into which the transcripts might be divided to compute the level of agreement that might occur by chance.
} 
significantly in their SPT Confidence $(M=.62$ vs. $M=.54)$ or SPT Importance $(M=.77$ vs. $M=.71)$. Unfortunately, due to the uneven gender distribution within the student population (only two of the 13 students were female) we were unable to disentangle the effects of age versus gender.

It is also worth noting (perhaps as a partial consequence of this heterogeneity) that there was substantial variability in the number of times participants identified a factor that motivated them to engage in SPT in a specific instance. Participants identified as few as 2 and as many as 44 specific motivations, with adults identifying about twice as many specific factors that triggered them to engage in SPT $\left(M s=15.40\right.$ versus 7.38; $t_{(26)}=2.94$, $p=.007$; Cohen's $d=1.14$ ). See Table 1 for all descriptive statistics and correlations between these measures.

$* * * * * * * * * * * * * * * * * * * * * *$

Insert Table 1 about here

\section{Specific factors influencing social perspective taking motivation}

Our interviews revealed seven factors that consistently and positively influenced participants' SPT motivation (i.e., their presence almost always contributed towards their engaging in the SPT process), three that were mixed (i.e., their presence sometimes increased and sometimes decreased SPT motivation), and three that were predominantly negative. See Table 2 for a summary of the specific factors triggering engagement in SPT.

Insert Table 2 about here

Positive motivational factors. Many participants reported being motivated to engage in SPT when a target or a situation was viewed as particularly "high stakes." This perception could occur for multiple reasons. Sometimes the perceiver cared deeply about the target. As one participant noted, “The primary fact is that he's my son, so I think it just overshadows everything else.” In other high-stakes instances, the target was perceived as potentially threatening (as was sometimes the case for the customs officials and army 
interrogators). One target was perceived by one of the psychologists as extremely high stakes because she was a client who was suicidal.

Prosocial goals were also frequently mentioned as spurring participants to engage in SPT. For example, one teacher described a transformation during her undergraduate years as increasing her motivation to help others, and she saw SPT as a means towards that end. "I became a Christian and my whole perspective on life changed. From that point on, I understood why it was so important for me to help others. I developed a real compassion and empathy for others and that definitely coincides with when I started teaching.” Although this change in orientation impacted this teacher's perceptions on a relatively global level, other prosocial goals were more localized to particular events. For example, one student described being motivated to figure out what was wrong with an upset family member and how he could help, "It was obvious that he was kind of frustrated...I just felt like, oh, my stepfather needs help so I should probably just find out (what he needs).”

A desire for situational knowledge also motivated participants to engage in SPT. Particularly under conditions of uncertainty, some individuals were motivated to figure out the thoughts and feelings of others in order to learn more about local norms and how they should interact. In one example, a customs official's job changed abruptly as the result of several agencies merging. This person was highly motivated to engage in SPT in order to adapt to a new job and new co-workers. As he recalled, “There was a whole new way of doing business. I really had to figure out how to go on with the program and where my niche was going to be.”

Participants reported that pursuing certain relationship goals often motivated them to engage in SPT. As one of the psychologists noted, "A huge motivator for me in trying to understand people is that I want to feel connected to them and I want them to feel connected to me.” Specifically, individuals used SPT when trying to initiate a new relationship, maintain an existing one, or repair one that was in trouble. At the initiation stage of a relationship, one student recalled meeting a new student at her school and thinking, "Oh this guy is really interesting. I'm gonna go find out. He seemed to be always laughing, always happy. He seemed very puzzling. It's like, is there more to this guy? I want to know.” As an illustration of maintaining a relationship, a different student described being motivated to take the perspective of two friends who were fighting with 
each other as a means to maintaining both relationships. The student explained, "Since they were both my friends, I didn't want to be one-sided. I wanted to avoid getting too involved but still get enough information to know what happened between the two of them." When participants were motivated to repair damaged relationships, they often employed strategies that required substantial effort on their part (e.g., setting up a face to face meeting with the target rather than talking over the phone).

Some participants were motivated to engage in SPT as a result of their desire for social influence. In other words, when they wanted to obtain cooperation, compliance, or otherwise influence another person, they were often motivated to take that person's perspective. While working abroad, one educator described being motivated to meet with families in order to better take their perspectives before asking for their cooperation on a project. She stated, "I knew eventually I would have to ask them for a lot of information, but I decided I want to get to know them better and show them that I was actually really interested in them and also their families and also their organizations. If I have a good relationship, they might be willing to go kind of above and beyond to help me out.”

Some participants identified an intrinsic interest in taking the perspective of others. In the same way that motivation theorists have described people as having a certain "need for achievement” (e.g., McClelland, 1987), some of our participants described themselves as generally being curious about the mental worlds of others. One teacher turned SPT into a hobby:

I like to watch people. I like to even just sit in the subway sometimes and just watch, you know, how people interact. And I wonder, “What could the context be of this interaction?” It's fascinating to me... I watch people a lot. I like to sit in the lunchroom at school and just watch the kids interact, like watch how they make the decision coming away from the microwave where they're gonna sit.

Almost paradoxically, certain participants were motivated to take the perspective of others as a means to acquiring self-knowledge. In particular, some participants found SPT to be a useful means of learning how they were perceived by others and consequently reported being more motivated to engage in SPT. As a prototypic example, one teacher described being particularly motivated to try to understand the people who were interviewing her for a job as a means to determining their thoughts about her (and especially whether she would receive an offer!). 
Mixed motivational factors. Emotion regulation was a key theme for over $75 \%$ of participants. They mentioned that regulating their emotions influenced their SPT motivation in two ways - as a means and as an end goal. Usually, participants described emotion regulation as a means to engaging in SPT and typically reported instances when they were unmotivated to engage in SPT because of insufficient emotion regulation. One participant described his lack of motivation to take the perspective of his wife's boss, "I don't know why she treated my wife the way she did and I never tried to figure it out. All I know is that she would make my wife very upset and that upset me. To this day, I can't stand the sight of her." In a few instances, participants were motivated to engage in SPT because they were pursuing a goal to regulate their own emotions or the emotions of others. For instance, one student described being motivated to take his father's perspective in order to regulate his own frustration about being forced to apply to college when he preferred to get a job after graduating from high school. In other words, he was motivated to take his father's perspective in the hope that seeing the positive aspects of his father's point of view would make him less frustrated. One employer was motivated to use SPT as a means to regulating an employee's emotions when denying his request to change work hours. Our participant recalled that something was, "telling me he’s feeling a sense of overload and I really don't want to hit him with it that afternoon.” By waiting a couple of days before delivering the disappointing news, the boss was trying to regulate his employee's emotions by keeping him calmer. Thus, our participant was motivated to take the employee's perspective as a means to regulate the employee's emotions. In sum, although participants most frequently noted their own lack of emotion regulation as a motivational barrier to engaging in SPT, they also described instances of being motivated to engage in SPT as a means to regulating their own emotions or even the emotions of others.

A second factor that motivated SPT in positive and negative directions was the perceiver's identity or role. In this context, we use "identity" to characterize a continuum, from temporarily assumed identities or roles (e.g., dinner guest at a friend's home) to much more permanent identities (e.g., one’s ethnic identity). People’s identities can exist as objective fact (e.g., Aaron is a teacher) or in the subjectivity of their own minds (e.g., Betty thinks she is the best teacher in the school). One participant described his professional 
identity as follows, "Being a trial lawyer, I have to try to think about what other people are thinking, especially jurors. I have to try to appreciate their perspective. I try to tailor my cases to what they understand.” The same participant noted that a second role was also a positive motivating force for him, "Having a child with disabilities helps. I'm gonna appreciate the perspective of, of what my son was thinking.” By contrast, another participant was often in the role of listening to his subordinates excuses for their misdeeds. In these instances he perceived his role explicitly as not requiring SPT, but rather enforcing the consequences of these rule violations.

Familiarity was a third factor that sometimes motivated and sometimes inhibited SPT. Relatives were often mentioned as targets that the perceivers in our study were particularly motivated to understand. However, this factor also worked in the opposite direction. Two different participants mentioned not being particularly motivated to take the perspective of their brothers because of an implicit assumption that their relationship as siblings would always be there. On the other hand, one participant noted that she was highly motivated by a lack of familiarity when meeting strangers abroad, “...because I’m not from that culture, and so I don't know exactly what's needed, and I don't always know exactly what the right response would be.”

Negative motivational factors. Several participants noted that a lack of energy actively inhibited their motivation to engage in SPT. Although certainly there are times when we infer the thoughts and feelings others relatively easily and automatically, SPT often requires energy and effort (Hodges \& Wegner, 1997). During those times that participants lacked energy, they often noted that they were particularly unmotivated to engage in SPT. In noting a particular SPT attempt that lacked effort, one educator attributed much of the problem to a lack of energy, "I'm tired, so I get a little cranky, and it was first thing in the morning too, so I hadn’t finished my coffee yet.”

Hubris was also noted as an inhibiting motivational factor. Participants noted that this factor was distinct from mere confidence because it entailed an element of righteousness. One educator described the times when she was least motivated to engage in SPT as, “When I have a lot of hubris and think that I'm right. When I'm so convinced that I'm right, and I am belittling the other person's intelligence in my head.” Hubris also 
functioned in almost a pre-emptive fashion. For example, one student described not wanting to take her sister's perspective, "because I wanna be right.”

A final motivational inhibitor of SPT was the cognitive load that participants felt. As a perceiver has more and more to keep track of mentally, it becomes increasingly challenging to try to engage in SPT. Teachers noted that SPT was particularly hard in large classes where they had to take the perspective of many students at the same time. One noted, “I don't have the time to spend looking at each kid and looking at their responses to me. In a class of fifteen it's very different than when I'm in a class of twentythree. This teacher also noted that time played a role as well in that she simply did not have time to read the non-verbal cues of so many students in larger classes.

Table 3 shows the relative frequencies of each of the motivational factors described above. With the modest size and idiosyncratic nature of the sample, it is risky to read too much into differences between our adult and student samples regarding what specific factors motivated them to engage in SPT. However, the two groups did differ on three of these factors which suggests that there may be trends in how these groups differ. Specifically, the adults were more motivated to engage in SPT when they perceived a situations as high stakes $\left(\chi_{3}{ }^{2}=8.19, p=.04\right)$ and when they were trying to influence others $\left(\chi_{3}^{2}=9.62, p=.02\right)$. Adults also mentioned that their role influenced their motivation to engage in SPT to a greater degree than students $\left(\chi_{6}{ }^{2}=22.10, p=.001\right)$.

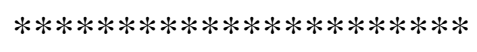

Insert Table 3 about here

\section{Discussion of Educational Implications for Theory and Practice}

This study takes a preliminary step within a larger research agenda whose ultimate goal is to teach individuals in schools how to improve their SPT. While prior research has demonstrated the importance of SPT for educational outcomes, little is known about the process of SPT itself. This study enriches our understanding of how the SPT process begins by identifying the specific motivational triggers of SPT. Through the taxonomy in Table 2, we have attempted to distill those factors that impact SPT motivation. While focusing particularly on school settings, we frame our discussion around the central theme 
that there are many avenues, combinations of avenues, and interactions between avenues that motivate individuals to engage (or not engage) in SPT. We anticipate that these findings will provide a foundation for facilitating the teaching of SPT to different school populations as well as for directing future research efforts.

\section{Multiple Motivational Avenues to SPT}

One clear theme to emerge from our data is that multiple pathways exist through which individuals might be motivated to engage in SPT. This finding has important practical implications for individuals in schools. Perhaps most important is that those individuals who appear unmotivated to engage in SPT might be motivated through an alternative pathway. In concrete terms, imagine a teacher who views discerning the thoughts and feelings of her students as unimportant. She thinks that SPT is more the domain of school counselors; it is not part of her role. Our results indicate that there may be other avenues for motivating this teacher to engage in SPT. Perhaps an administrator could encourage her to see her subject area as high stakes for students to learn. If she comes to see SPT as a means to understanding where her students are struggling with regard to the important content, the teacher may become more motivated to engage in the SPT process.

A second important implication arises in situations where an individual is trying to get a group to engage in SPT (e.g., an administrator leading a faculty meeting, or a teacher and a class) - a single specific SPT motivation may not resonate with all group members, i.e., different individuals will be motivated by different factors. For example, some participants were intrinsically interested in learning about others, and this curiosity motivated them to engage in the SPT process. Other participants never mentioned this factor and showed few signs of such curiosity. Thus, educators working with groups may wish to offer multiple motivational "hooks" to get a broader cross section of the group they are working with to engage in SPT.

In addition to these practical implications, researchers might shed more light on how these multiple avenues work for different individuals. One important approach would be to identify whether certain specific SPT motivations tend to work for most individuals while others are more idiosyncratic. Knowing which specific SPT motivations are most 
likely to trigger an individual to engage in SPT would be tremendously valuable in helping teachers prioritize different approaches to bolstering their students' SPT motivation. A second, equally valuable strand of research might explore whether certain specific SPT motivations tend to be more compelling for certain groups. Our findings suggest slightly different trends between adults and students for certain motivational factors. Teasing apart the extent to which these differences are a consequence of developmental stage, differences in SPT aptitude, or some other reason - perhaps gender differences in SPT motivation (see Klein \& Hodges, 2001) - would be fruitful to investigate. It is not hard to imagine that administrators, counselors, teachers, and students are frequently motivated to engage in SPT by different factors.

\section{Combinations of Avenues}

In addition to documenting the existence of many avenues through which one might be motivated to engage in SPT, our participants also illustrated that these motivational pathways often operate in concert. For example, the participant who described wanting to get information from families to build a relationship with them before she needed to ask favors of them was simultaneously pursuing influence and relationshipbuilding goals. When specific SPT motivations co-occur, there may be an additive effect that produces greater SPT motivation than if only a single motive is present.

To the extent that these specific factors co-occur, they may represent aligned goals (Ford, 1992). As a consequence, they may produce stronger motivation for individuals to engage in SPT. From a practical standpoint, principals who see it as part of their role to understand parents' concerns and want to better grasp the environments in which their students are being raised might be more motivated to take parents' perspectives than principals who are only motivated by one of those factors. Professional development activities in which teachers work in pairs to reflect on their practice might activate two motivational avenues (a desire for self-knowledge about their teaching and relationship goals with their partner) as compared to activities that do not include a reflective component or that have teachers work individually.

Although these practical implications are potentially quite important, the existence of these types of additive effects needs to be documented empirically. A naturalistic 
approach to conducting such research could take advantage of collaborative debate activities sometimes used in classrooms. For example, "constructive controversies" (Johnson \& Johnson, 2009) have a robust reputation as a fruitful way of motivating students to engage in SPT. In this exercise, two students debate an important issue against another pair by: presenting their side of the argument, listening to the opposing argument, and then engaging in an open debate. Then, to promote SPT, the pairs switch roles and argue against the position they initially espoused. Thus, in addition to students being motivated to engage in the SPT process because it is part of their assigned role, they are motivated for the prosocial reasons of helping their teammate as well as trying to influence and persuade the opposing team. To ascertain which combinations of these specific factors build upon one another, researchers might restructure the constructive controversies to remove certain factors or add new ones based on the taxonomy presented here and assess students' resultant SPT motivation.

\section{Interactions between Avenues}

Our interviews indicate that the specific motivational factors often interacted with one another. Whether the factors of identity, emotion regulation, and familiarity motivated or inhibited the SPT process often depended on interactions with other factors. For instance, a number of participants described familiarity as a positive motivator of SPT when a familiar target was somebody they wished to help. Yet, when those prosocial goals were absent, there was often a lack of motivation to take the perspective of that familiar target. As a particularly illustrative example of how complicated these types of interactions can be, one of the participants from the Army was questioning a terrorist suspect who, according to the interrogator, was lying about his reasons for being in Afghanistan. In describing the situation, our participant indicated that this was (1) an unfamiliar individual from a familiar culture (2) who was a very high-stakes perspective taking target and (3) who was trying to provoke him emotionally by "telling stories.” In his (4) role as an interrogator he felt he needed to (5) build a relationship with this suspect but ultimately had to (6) influence him to get whatever information he could. In this particular instance, the net result of the (1) familiarity by (2) high stakes by (3) emotion regulation by (4) identity by (5) relationship by (6) social influence interaction was that our 
participant was highly motivated to understand the target's perspective. Imagining a parallel situation with a teacher and multiple students helps illustrate how complex the interactions of these specific factors can be during classroom interactions.

In the absence of more research in this particularly complicated area of SPT motivation, the practical implications are limited. However, given findings such as the interaction between the familiarity and prosocial factors, it seems reasonable to advocate that educators who are trying to promote more SPT within a school community at least be wary of the potential for these complex interactions.

Given the large number of factors, combinations of factors, and interactions between factors, there is much for researchers to explore within this domain. Davis (2005) articulately conceptualizes what may be the most important task for future researchers: to figure out which specific SPT motivations form optimal natural combinations. In other words, to maximize the number of people within a school community who engage in SPT and the frequency with which they do so, it would be tremendously helpful for scholars to identify effective combinations of motivations that work well for most people most of the time.

\section{Limitations}

Two limitations are likely to be particularly concerning to readers. One question skeptical readers may have is whether our participants could have had sufficient insight into their own cognitive processes to report on their SPT habits during the interviews particularly in light of past research questioning the validity of self-reports (e.g., Nisbett \& Wilson, 1977). While this is an important limitation, it should not be over-stated. Nisbett and Wilson's oft-cited article has been used to critique self-reports of all kinds. They provide compelling illustrations that people are poor self-reporters of certain phenomena

such as the extent to which they were affected by primacy or recency biases. However, they do not address self-reports of more cognitively accessible phenomena such as feelings of happiness where self-reports are likely to provide the best measures of any currently available tool (Gilbert, 2006). Although having our participants reflect on SPT instances in the past probably lies between these two extremes, we went to some lengths to facilitate the self-reporting process. For example, participants focused and reflected on their SPT 
habits and patterns in a structured way for two hours. In the interviews, we guided participants to describe specific past events rather than speaking in generalities. Both the length of time they were allowed to reflect on the topic and the concrete focus should have facilitated their memory search and bolstered the accuracy of their self-reports (Tourangeau, Rips, \& Rasinski, 2000).

Second, because this research represents an initial attempt at mapping the range of specific motivational factors on SPT, it seems inevitable that these categories will undergo further refinement. Although our sample included a wide cross-section of individuals who reported on both extreme and mundane SPT episodes, it is possible that some specific motivations were not experienced or not reported by those in our sample. Furthermore, some specific motivations that we have uncovered may be sufficiently rare so as not to warrant mentioning in future taxonomies. Other motivations may be commonly used by individuals not represented in the sample. Our hope is that the present research provides a foundation from which those refinements can be made and gives a sense of which motivations might be present in any given situation.

\section{Conclusion}

As the scholarship on SPT develops, better understanding its component parts is essential to gaining a comprehensive picture of the SPT process and ultimately teaching this important aptitude within schools. The present work serves to illuminate a critical facet of that larger process - what motivates individuals to engage in SPT in specific situations. In combination with the existing work on SPT dispositions, SPT accuracy, and experimental work on SPT, our hope is that the present research will contribute to a comprehensive understanding of this aptitude.

There appears to be no shortage of interpersonal misunderstandings between individuals or groups in schools (or elsewhere in the world for that matter). As Elvis notes, people are often quick to “abuse, criticize and accuse.” Thus, this work on understanding the SPT process and ultimately teaching individuals to improve their SPT aptitude seems particularly critical. 


\section{References}

Ambady, N., \& Rosenthal, R. (1993). Half a minute: Predicting teacher evaluations from thin slices of nonverbal behavior and physical attractiveness. Journal of Personality and Social Psychology, 64(3), 431-441.

Ames, D. (2004). Inside the mind-reader's toolkit: Projection and stereotyping in mental state inference. Journal of Personality and Social Psychology, 87(3), 340-353.

Ames, D., \& Kammrath, L. (2004). Mind-reading and metacognition: Narcissism, not actual competence, predicts self-estimated ability. Journal of Nonverbal Behavior, 28(3), 187-209.

Barnette, J. J. (2005). ScoreRel CI: An Excel program for computing confidence intervals for commonly used score reliability coefficients. Educational and Psychological Measurement, 65(6), 980-983.

Batson, C. D., Early, S., \& Salvarani, G. (1997). Perspective taking: Imagining how another feels versus imagining how you would feel. Personality and Social Psychology Bulletin, 23(7), 751-758.

Batson, C. D., Sager, K., Garst, E., Kang, M., Rubchinsky, K., \& Dawson, K. (1997). Is empathy-induced helping due to self-other merging? Journal of Personality and Social Psychology, 73(3), 495-509.

Bernieri, F. J. (1991). Interpersonal sensitivity in teaching interactions. Personality \& Social Psychology Bulletin, 17(1), 98-103.

Corcoran, K. O., \& Mallinckrodt, B. (2000). Adult attachment, self-efficacy, perspective taking, and conflict resolution. Journal of Counseling \& Development, 78(4), 473483.

Davis, M. H. (1983). Measuring individual differences in empathy: Evidence for a multidimensional approach. Journal of Personality and Social Psychology, 44(1), 113-126.

Davis, M. H. (2005). A 'constituent' approach to the study of perspective taking: What are its fundamental elements? In B. F. Malle \& S. D. Hodges (Eds.), Other minds: How humans bridge the divide between self and others. (pp. 44-55). New York: Guilford Press.

Davis, M. H., \& Franzoi, S. L. (1991). Stability and change in adolescent selfconsciousness and empathy. Journal of Research in Personality, 25(1), 70-87.

Eccles, J. S., Wigfield, A., \& Schiefele, U. (1998). Motivation to succeed. In N. Eisenberg (Ed.), Handbook of child psychology (Vol. 4, pp. 1017-1095). New York: John Wiley \& Sons.

Enright, R. D., \& Deist, S. H. (1979). Social perspective taking as a component of identity formation. Adolescence, 14(55), 517-522.

Ford, M. E. (1992). Motivating humans: Goals, emotions, and personal agency beliefs. Newbury Park, CA: Sage Publications.

Galinsky, A. D., Maddux, W. W., Gilin, D., \& White, J. B. (2008). Why it pays to get inside the head of your opponent: The differential effects of perspective taking and empathy in negotiations. Psychological Science, 19(4), 378-384.

Galinsky, A. D., \& Moskowitz, G. B. (2000). Perspective-taking: Decreasing stereotype expression, stereotype accessibility, and in-group favoritism. Journal of Personality and Social Psychology, 78(4), 708-724. 
Gehlbach, H. (2004a). A new perspective on perspective taking: A multidimensional approach to conceptualizing an aptitude. Educational Psychology Review, 16(3), 207-234.

Gehlbach, H. (2004b). Social perspective taking: A facilitating aptitude for conflict resolution, historical empathy, and social studies achievement. Theory and Research in Social Education, 32(1), 39-55.

Gehlbach, H. (2005, April). How confident should we be in confidence? The role of expectancies in social perspective-taking. Paper presented at the annual meeting of the American Educational Research Association, Montreal.

Gehlbach, H., Brown, S. W., Ioannou, A., Boyer, M. A., Hudson, N., Niv-Solomon, A., et al. (2008). Increasing interest in social studies: Stimulating simulations, selfefficacy, and social perspective taking. Contemporary Educational Psychology, 33(4), 894-914.

Gilbert, D. T. (2006). Stumbling on happiness (1st ed.). New York: Alfred A. Knopf.

Gleason, K. A., Jensen-Campbell, L. A., \& Ickes, W. (2009). The role of empathic accuracy in adolescents' peer relations and adjustment. Personality and Social Psychology Bulletin, 35(8), 997-1011.

Gruhn, D., Rebucal, K., Diehl, M., Lumley, M., \& Labouvie-Vief, G. (2008). Empathy across the adult lifespan: Longitudinal and experience-sampling findings. Emotion, 8(6), 753-765.

Halberstadt, A. G., \& Hall, J. A. (1980). Who's getting the message? Children's nonverbal skill and their evaluation by teachers. Developmental Psychology, 16(6), 564-573.

Hall, J. A., Andrzejewski, S. A., \& Yopchick, J. E. (2009). Psychosocial correlates of interpersonal sensitivity: A meta-analysis. Journal of Nonverbal Behavior, 33(3), 149-180.

Hall, J. A., Blanch, D. C., Horgan, T. G., Murphy, N. A., Rosip, J. C., \& Schmid Mast, M. (2009). Motivation and interpersonal sensitivity: Does it matter how hard you try? Motivation and Emotion, 33(3), 291-302.

Hodges, S. D., Kiel, K. J., Kramer, A. D. I., Veach, D., \& Villanueva, B. R. (2010). Giving birth to empathy: The effects of similar experience on empathic accuracy, empathic concern, and perceived empathy. Personality and Social Psychology Bulletin, 36(3), 398-409.

Hodges, S. D., \& Wegner, D. M. (1997). Automatic and controlled empathy. In W. J. Ickes (Ed.), Empathic accuracy (pp. 311-340). New York: The Guilford Press.

Ickes, W. J. (2003). Everyday mind reading: Understanding what other people think and feel. Amherst, NY, US: Prometheus Books.

Ickes, W. J. (Ed.). (1997). Empathic accuracy. New York: The Guilford Press.

Johnson, D. W., \& Johnson, R. T. (2009). Energizing learning: The instructional power of conflict. Educational Researcher, 38(1), 37-51.

Juvonen, J. (2007). Reforming middle schools: Focus on continuity, social connectedness, and engagement. Educational Psychologist, 42(4), 197-208.

Keating, D. P. (1990). Adolescent thinking. In S. S. Feldman \& G. R. Elliott (Eds.), At the threshold: The developing adolescent. (pp. 54-89). Cambridge: Harvard University Press. 
Klein, K. J. K., \& Hodges, S. D. (2001). Gender differences, motivation, and empathic accuracy: When it pays to understand. Personality and Social Psychology Bulletin, 27(6), 720-730.

Krueger, J. I. (2007). From social projection to social behaviour. European Review of Social Psychology, 18, 1-35.

Mayer, J. D., Salovey, P., \& Caruso, D. R. (2008). Emotional intelligence: New ability or eclectic traits? American Psychologist, 63(6), 503-517.

McClelland, D. C. (1987). Human motivation. Cambridge, MA: Cambridge University Press.

Mischel, W., \& Shoda, Y. (1995). A cognitive-affective system theory of personality: Reconceptualizing situations, dispositions, dynamics, and invariance in personality structure. Psychological Review, 102(2), 246-268.

Nickerson, R. S. (1999). How we know--and sometimes misjudge--what others know: Imputing one's own knowledge to others. Psychological Bulletin, 125(6), 737-759.

Nisbett, R. E., \& Wilson, T. D. (1977). Telling more than we can know: Verbal reports on mental processes. Psychological Review, 84(3), 231-259.

Presley, E. (1970). Walk a Mile in My Shoes. On On Stage: February 1970. Las Vegas: BMG.

Realo, A., Allik, J., Nolvak, A., Valk, R., Ruus, T., Schmidt, M., et al. (2003). Mindreading ability: Beliefs and performance. Journal of Research in Personality, 37(5), 420-445.

Richardson, D. R., Green, L. R., \& Lago, T. (1998). The relationship between perspectivetaking and nonaggressive responding in the face of an attack. Journal of Personality, 66(2), 235-256.

Robbins, J. M., \& Krueger, J. I. (2005). Social projection to ingroups and outgroups: A review and meta-analysis. Personality and Social Psychology Review, 9(1), 32-47.

Selman, R. L. (1975a). Level of social perspective taking and the development of empathy in children: Speculations from a social-cognitive viewpoint. Journal of Moral Education, 5(1), 35-43.

Selman, R. L. (1975b). Taking another's perspective: Role-taking development in early childhood. Child Development, 42(6), 1721-1734.

Tourangeau, R., Rips, L. J., \& Rasinski, K. A. (2000). The psychology of survey response. New York: Cambridge University Press.

VanSledright, B. (2001). From empathetic regard to self-understanding: Im/positionality, empathy, and historical contextualization. In O. L. Davis, E. A. Yeager \& S. J. Foster (Eds.), Historical empathy and perspective taking in the social studies (pp. 51-68). Lanham, Md.: Rowman \& Littlefield.

Verhofstadt, L. L., Buysse, A., Ickes, W., Davis, M., \& Devoldre, I. (2008). Support provision in marriage: The role of emotional similarity and empathic accuracy. Emotion, 8(6), 792-802.

Wentzel, K. R. (1997). Student motivation in middle school: The role of perceived pedagogical caring. Journal of Educational Psychology, 89(3), 411-419. 


\section{Author Note:}

This research was made possible through a generous grant from the William F. Milton Fund at Harvard University. The authors are extremely indebted to Cynthia Wang, Sophie Beran, and Dennis Lam, for their work on this project. Earlier drafts of this manuscript were greatly improved by the thoughtful comments of Grace Ahn, Judy Hall, Monica Higgins, Stuart Karabenick, Benjamin Kirshner, and Sally Theran - we are greatly appreciative. 
Table 1. Means, standard deviations, ranges, and intercorrelations among social perspective taking variables

\begin{tabular}{lrrlllll}
\hline & Mean & SD & Range & 1 & 2 & 3 & 4 \\
\hline 1. SPT propensity & .68 & .16 & $.28 \sim .94$ & -- & & & \\
2. SPT importance & .74 & .15 & $.43 \sim .96$ & $.54^{* *}$ & -- & & \\
3. SPT confidence & .58 & .19 & $.22 \sim .84$ & .33 & .21 & -- & \\
$\begin{array}{l}\text { 4. SPT accuracy } \\
\begin{array}{l}\text { 5. Total number of motivation } \\
\text { factors mentioned }\end{array}\end{array}$ & 11.68 & 8.16 & $2 \sim 44$ & $.55^{* *}$ & .33 & .18 & .27 \\
\hline
\end{tabular}

$N=27-30$

$* p<.05^{* *} p<.01 \quad * * * p<.001$ 
Table 2: Motivators of social perspective taking

\begin{tabular}{|c|c|}
\hline Factors & Description \\
\hline Positive motivational factors & The presence of these factors generally foster motivation to engage in SPT. \\
\hline High stakes target/situation & $\begin{array}{l}\text { Perceivers are motivated to engage in SPT because they feel that the situation and/or the } \\
\text { target are especially important (e.g., engaging in SPT as a means to protecting the self or } \\
\text { others). }\end{array}$ \\
\hline Prosocial goals & Perceivers are motivated by a desire to help the target and/or others in the situation. \\
\hline Desire for situational knowledge & $\begin{array}{l}\text { Perceivers are motivated to engage in SPT to better understand a situation and its norms } \\
\text { and/or to reduce their own uncertainty. }\end{array}$ \\
\hline Relationship goals & $\begin{array}{l}\text { Perceivers are motivated to engage in SPT to achieve certain relationship goals (e.g., } \\
\text { initiating, maintaining, or repairing a relationship) with the target and/or others. }\end{array}$ \\
\hline Social influence & $\begin{array}{l}\text { Perceivers may engage in SPT to determine how to obtain the target's cooperation or } \\
\text { compliance or to influence the target more generally. }\end{array}$ \\
\hline Intrinsic interest & Perceivers feel a curiosity and/or need to understand others. \\
\hline Desire for self-knowledge & $\begin{array}{l}\text { Perceivers engage in SPT to understand more about themselves or how their actions are } \\
\text { interpreted by others. }\end{array}$ \\
\hline Mixed motivational factors & Presence of these factors can foster or inhibit SPT motivation. \\
\hline Emotion regulation & $\begin{array}{l}\text { Perceivers may be motivated to engage in SPT to help regulate their emotions (or the } \\
\text { emotions of others) or may be unmotivated to engage in SPT due to a lack of emotion } \\
\text { regulation. }\end{array}$ \\
\hline Identity & $\begin{array}{l}\text { Perceivers are motivated to engage in SPT to fulfill a temporary role (e.g., advising a friend) } \\
\text { or a more permanent identity (e.g., caring parent). Certain roles/identities may motivate } \\
\text { perceivers not to engage in SPT (e.g., not wanting to be understanding of excuses for failure) }\end{array}$ \\
\hline
\end{tabular}


Familiarity

Negative motivational factors

Lack of energy

Hubris

Cognitive load
Perceivers may be motivated to take the target's perspective because they know the target well. However, perceivers may be unmotivated to engage in SPT because the target is so familiar that his or her perspective can be assumed.

Presence of these factors generally inhibit motivation to engage in SPT

Perceivers lack the energy to engage in SPT.

Perceivers feel sufficient conviction that their point of view is correct that they do not need to engage in SPT.

Perceivers have too much on their mind or are contending with too many distractions to engage in SPT. 
Table 3. Frequency of mentioning positive, mixed, and negative factors on motivation

\begin{tabular}{|c|c|c|c|c|c|}
\hline Positive factors & $\begin{array}{l}\text { Number of people } \\
\text { mentioning the } \\
\text { factor } \\
\text { (out of 28) }\end{array}$ & $\begin{array}{l}\text { Total } \\
\text { frequency }\end{array}$ & $\begin{array}{l}\text { Mean number } \\
\text { of mentions } \\
\text { per person } \\
\text { (out of 28) }\end{array}$ & SD & $\begin{array}{l}\text { Maximum } \\
\text { mentions by a } \\
\text { single person }\end{array}$ \\
\hline High stakes target/situation & 22 & 32 & 1.14 & .85 & 3 \\
\hline Prosocial goals & 19 & 47 & 1.68 & 1.79 & 8 \\
\hline Desire for situational knowledge & 18 & 37 & 1.32 & 1.59 & 7 \\
\hline Relationship goals & 15 & 28 & 1.00 & 1.15 & 4 \\
\hline Social influence & 14 & 23 & .82 & .98 & 3 \\
\hline Intrinsic interest & 8 & 12 & .43 & .79 & 3 \\
\hline Desire for self-knowledge & 8 & 9 & .32 & .55 & 2 \\
\hline \multicolumn{6}{|l|}{ Mixed factors } \\
\hline Emotion regulation & 24 & 51 & 1.82 & 1.31 & 5 \\
\hline Identity & 18 & 50 & 1.79 & 1.83 & 6 \\
\hline Familiarity & 12 & 23 & .82 & 1.22 & 4 \\
\hline \multicolumn{6}{|l|}{ Negative factors } \\
\hline Low energy & 6 & 7 & .25 & .52 & 2 \\
\hline Hubris & 4 & 5 & .28 & .48 & 2 \\
\hline Cognitive load & 3 & 3 & .11 & .32 & 1 \\
\hline
\end{tabular}




\section{Appendix}

1) SPT-Propensity - 9 items; $\alpha=.77, \mathrm{~m}=3.67, \mathrm{sd}=.62$

Response scale:

almost once in sometimes frequently almost all

never a while the time

Items:

When you are angry at someone, how often do you try to "put yourself in his or her shoes"?

How often do you attempt to understand your friends better by trying to figure out what they are thinking?

How often do you try to understand what people who you dislike are thinking?

When you accidentally upset someone you have just met, how often do you imagine how that person understood the situation?

When you argue with your friends, how often do you try to imagine how they are feeling?

Before forming an opinion about a disagreement others are having, how often do you try to look at all sides of that disagreement?

How often do you try to come up with more than one explanation for why someone else acted as they did?

When making an important decision, how often do you consider the way other people might react to it?

Before you tell someone important news, how often do you try to imagine how they will react?

2) SPT-Confidence -8 items; $\alpha=.90, \mathrm{~m}=3.33, \mathrm{sd}=.76$

Response scale:

$\begin{array}{ccccc}\text { not at all } & \text { slightly } & \text { moderately } & \text { quite } & \text { extremely } \\ \text { confident } & \text { confident } & \text { confident } & \text { confident } & \text { confident }\end{array}$

$\underline{\text { Items: }}$

How confident are you that you can understand what strangers are thinking when you are talking with them?

When friends try to avoid talking about something that is bothering them, how confident are you that you can still figure out what is bothering them?

How confident are you that you can figure out how a family member is feeling when talking to them on the phone?

How confident are you that you can figure out how other people are feeling over email?

When you have a disagreement with someone, how confident are you that you can figure out what that person is thinking?

How confident are you that you can figure out what kind of mood somebody is in if you have just met them for the first time?

When talking with someone from a different background than your own, how confident are you that you can understand how that person views the situation?

How confident are you that you can tell if you have hurt someone's feelings? 
3) SPT-Importance -7 items; $\alpha=.73, \mathrm{~m}=3.96$, sd $=.58$

Response scale:

not at all

important

$$
\text { slightly }
$$

important moderately

important quite

important extremely

important

Items:

How important is it to understand your family members' opinions when working out disagreements with them?

In a disagreement with someone you dislike, how important is it for you to figure out what his/her point of view is?

When working on a project with somebody else, how important is it for you to figure out how that person thinks the project is going?

When talking to someone from a different culture than your own, how important is it for you to understand that person's point of view?

When a friend tries to avoid talking about his or her feelings, how important is it to you to figure out what his/her true feelings are?

When somebody is angry with you, how important is it for you to understand what $\mathrm{s} / \mathrm{he}$ is thinking?

When you think you know why a friend acted as s/he did, how important is it to you to figure out if you are correct? 